The authors reported no conflicts of interest.

The Journal policy requires editors and reviewers to disclose conflicts of interest and to decline handling or reviewing manuscripts for which they may have a conflict of interest. The editors and reviewers of this article have no conflicts of interest.

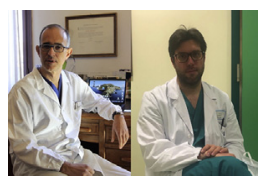

\section{A NEW TOOL IN THE ARSENAL}

\section{To the Editor:}

We would like to clarify 3 important issues regarding the AV Flow (MedEurope Srl, Bologna, Italy), a new cannula for antegrade selective cerebral perfusion (ASCP). Its unique feature consists in the possibility of guidewire introduction.

First of all, we want to discuss about the novelty of the AV Flow. This is not a modification of the well-known TRUE FLOW RDB cannula (MedEurope Srl). The concept behind them is completely opposite to each other, even if their aim (performing ASCP) is identical (Figure 1). Adjunctive surgical details have been previously published. ${ }^{1}$

Second, Murana and colleagues ${ }^{2}$ highlighted the "keepit-simple" principle. We agree with them in general. However, no doubt, aortic arch surgery is far from being simple, both in terms of surgical technique and devices to be chosen. Many different strategies have been described, with great variability distinguishing each major aortic center. In other words, even if the transverse arch is a "simple" anatomic structure (just a short vessel with 3 branches), aortic arch surgery is absolutely complex and far from being standardized. In some selected situations, nicely evidenced in the "hammers and nails" commentary, ${ }^{3}$ the use of the AV Flow can really simplify the procedure. Moreover, the Seldinger technique is one of the tools in the aortic surgeon's box. For this specific reason, our newly described surgical strategy is not complicated or somewhat uncertain at all.

Third, we briefly comment on the "time-consuming issue." The new cannula takes no more than a few minutes to be introduced. Furthermore, we strongly believe that the time spent for the ASCP setup before the circulatory arrest is well spent if the arrest time is consequently shorter (cannulas already in place plus potentially faster reimplantations being the AV Flow out of the anastomotic site).

Finally, every patient and surgical situation is different; therefore, we need a cannulation system that provides flexibility and options, like a good shop has lots of hammers for

Copyright (C) 2021 The Author(s). Published by Elsevier Inc. on behalf of The American Association for Thoracic Surgery. This is an open access article under the CC BY-NC-ND license (http://creativecommons.org/licenses/by-nc-nd/4.0/).
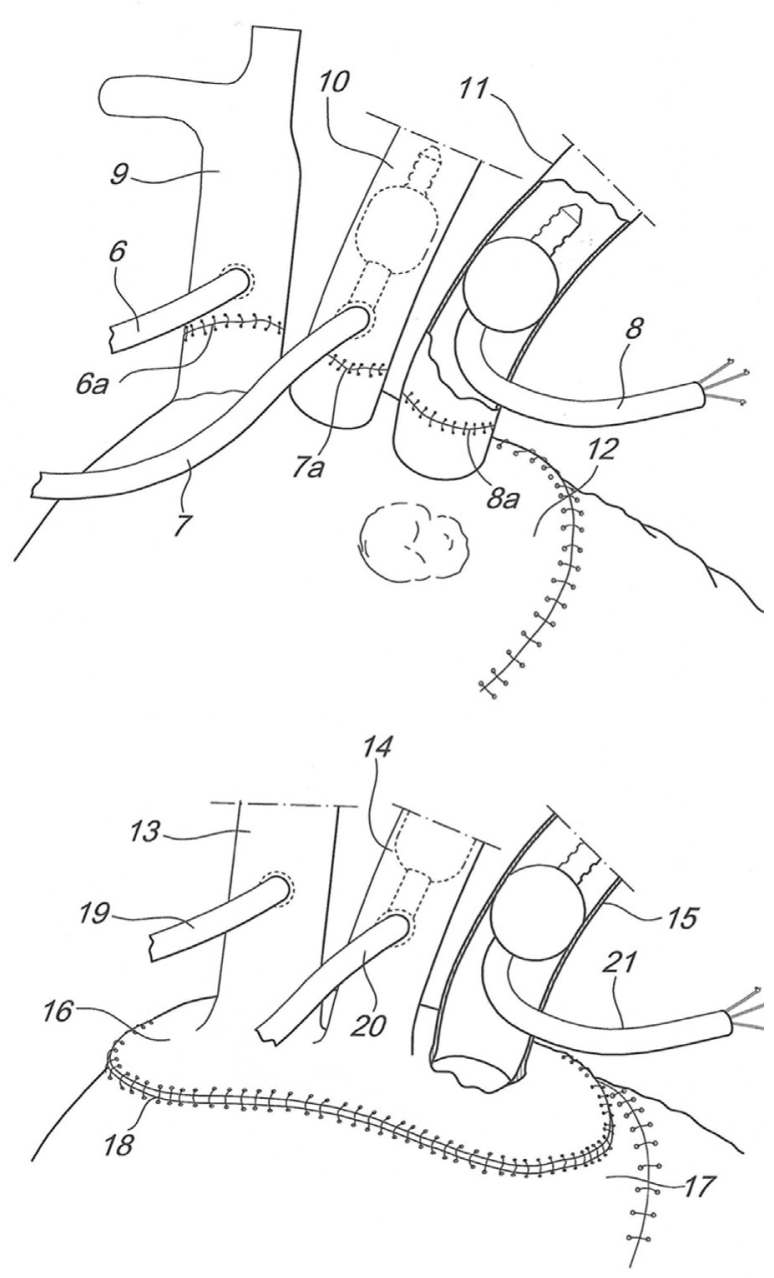

FIGURE 1. The author's original first schematic freehand drawing of the AV Flow cannula.

lots of nails. However, the commentary's criticism is important, to dot the i's on the contraindications of the procedure that must be kept in mind for safety reasons. In conclusion, these are not hair-splitting controversies because it's fundamental for any surgeon who wants to approach the aortic arch to have clear and precise indications and contraindications of all the tools in the ASCP arsenal.

Andrea Venturini, $M D, P h D^{a}$ Alan Gallingani, $M D^{a, b}$

${ }^{a}$ Cardiac Surgery Department Ospedale dell'Angelo

Venice-Mestre

${ }^{b}$ Cardiac Surgery Department

Ospedale Maggiore di Parma

Parma, Italy

\section{References}

1. Venturini A, Gallingani A, Asta A, Cannarella AM, Zanchettin C, Zoffoli G, et al A new cannula for antegrade selective cerebral perfusion. $J$ Thorac Cardiovasc Surg Tech. 2020;4:10-3. 
2. Murana G, Leone A, Pacini D. Commentary: antegrade cerebral perfusion using a "new" cannula: keep it simple! J Thorac Cardiovasc Surg Tech. 2020;4:14-5.
3. Hui DS, Calhoon JH. Commentary: hammers and nails. J Thorac Cardiovasc Surg Tech. 2020;4:16.

https://doi.org/10.1016/j.xjtc.2021.07.031 